\title{
Mitigating infectious diseases in Mizoram - A lesson from COVID-19
}

\author{
S. Sangthang ${ }^{1 *}$, Irene Lalhruaimawii ${ }^{2}$, Radhakrishnan Rajesh ${ }^{2}$ \\ ${ }^{1}$ Department of Immunohematology and Blood Transfusion, Kasturba Medical College, Manipal Academy of Higher Education, \\ Manipal, Karnataka, 576104, India \\ ${ }^{2}$ Department of Pharmacy Practice, Manipal College of Pharmaceutical Sciences, Manipal Academy of Higher Education, Manipal, \\ Karnataka, 576104, India
}

\begin{abstract}
COVID-19 pandemic has created huge havoc in public health in India and across the world. One among the small states of India, Mizoram lies between Bangladesh and Myanmar compelling a transmission risk of various infectious diseases across the boundary. The responsibilities of the authority to establish a screening and diagnostic laboratory is crucial to identify the infectious etiological agents, control, prevent morbidity, mortality, and burden of the diseases. We aim to discuss the need for an infectious disease surveillance system, the importance and role of advanced diagnostic and research laboratory in Mizoram, learning from SARS-CoV -2 pandemic.
\end{abstract}

Received 1 November 2020 Accepted 12 December 2020

*For correspondence: sangthangsingson@gmail.com

Contact us: sciencevision@outlook.com

Keywords: COVID-19, infectious diseases, surveillance, Mizoram.

\section{Introduction}

Illnesses caused by specific infectious pathogens or their toxic products result in spreading from an infected individual to a susceptible host through direct or indirect transmission, via vectors, and inanimate environment is termed infectious disease. ${ }^{1}$ Diseases whose incidence in humans have increased in the recent past or may threaten to rise in future are known as emerging infectious diseases (EIDs). EIDs include newly identified but undefined diseases in the past, as well as existing with new characteristic features, and introduction of diseases to a new environment. They also include diseases with new clinical presentation, resistance to available treatment; or an instant increase in the incidence and prevalence. The reappearance of an endemic disease that was once eradicated or controlled is known as a re-emerging infectious disease. ${ }^{2,3}$

Emerging and re-emerging infectious diseases have become an international health concern causing numerous health morbidity and mortality during outbreaks and epidemics. Due to advances and improved globalization, rapid air travel could be the route of spreading highly contagious diseases. Therefore, international collaboration and coordination in health setup is the need of an hour in detection, identification, and rapid response for controlling the transmission of diseases.

A coronavirus disease (COVID-19) caused by SARS CoV-2 from an outbreak in Wuhan City of China progressively turned pandemic; infected more than 55 million people around the world. ${ }^{4,5}$ SARSCoV-2 is a positive-sense RNA virus, with a genome length of approximately $30 \mathrm{~kb}$. It is classified under the order Nidovirales, family Coronaviridae, and genus Betacoronavirus by the International Committee on Taxonomy of Virus, Coronavirus Study 
Group. ${ }^{6,7}$ The novel coronavirus is one among the seven coronaviruses that infect human, which has an estimate of $50 \%$ and $79 \%$ genome similarity with Middle East Respiratory Syndrome coronavirus (MERS-CoV) and Severe Acute Respiratory Syndrome coronavirus (SARS-CoV- 1 ). ${ }^{8}$

Infectious diseases are a threat to all humans and a burden to health-promoting agencies in the world. Outbreak news and epidemics due to infectious pathogens are accessible from the World Health Organisation (WHO) Disease Outbreak News daily. ${ }^{9}$ Various international health organizations concerned related epidemics and outbreak of highly contagious diseases such as the SARS epidemic in 2002, H1N1 in 2009, Zika virus in 2016 and SARS-CoV-2, etc. with higher attack rate and transmission were commonly known to be caused by positive-sense RNA viruses. ${ }^{10}$

Mizoram is one of the small states of India with limited resources that grew progressively in developing technical, medical, and health infrastructures. Considering resource-limited states, we aim to discuss the current needs of an hour and a call for future in developing an infectious diseases surveillance, epidemiological research, and advanced diagnostic testing facility learning from COVID-19, to approach different outbreaks and epidemics prospectively.

\section{Clinical Features of COVID-19}

SARS-CoV-2 infection caused a respiratory tract illness particularly in the lower respiratory tract; severe and complicated cases need intensive care in a high dependency unit (HDU) with respiratory supports. Acute respiratory distress syndrome (ARDS) and other clinical complications were observed among the patients with underlying diseases and immunosuppressed. ${ }^{11}$ It can be transmitted through aerosol directly or indirectly; the median incubation period was described as 5.1 days (ranges from 2-14 days). ${ }^{12}$ Asymptomatic infection and transmission magnitude were reported variably, strong evidence for the frequency and transmissibility of the infection is yet to be determined. ${ }^{13,14}$ Patients with uncomplicated illness were with symptoms usually of upper respiratory tract infection such as mild fever, sore throat, cough (dry), nasal congestion, malaise, headache, etc. moderate illness present with cough, shortness of breath without a sign of pneumonia. ${ }^{15,16}$ Robust research on the natural history of infection and disease is important to identify the period of infectiousness, transmissibility, and the course of asymptomatic infection. ${ }^{17}$ Early laboratory diagnosis and clinical care are important for treatment and control of the spread of disease.

\section{Current Scenario in India}

The first COVID-19 case in India was diagnosed by National Institute of Virology Pune (NIV) on 30 January 2020 from a student in Kerala who returned from Wuhan, China. ${ }^{18}$ Currently, people with a history of international or interstate traveling were kept for quarantine or screened as per the Indian Council of Medical Research (ICMR) protocol (may vary in various states). Screening was done for all the suspected cases or through contact tracing. The first case of SARS-CoV-2 infected from Northeast India was identified from Manipur on 24 March 2020. Other northeast Indian states were neither free from SARS-CoV-2, Assam with the highest infected and mortality due to COVID-19. ${ }^{19}$ As of 28 November 2020, 1175 government and 986 private laboratories including Real-time RT-PCR and TrueNat or CBNAAT testing facilities had been approved by ICMR for diagnosis of SARS CoV-2 since pandemic. ${ }^{20}$ Ministry of Health and family welfare (MoHFW) and ICMR have taken a great step in surveillance screening and detection of the virus by setting up a diagnostic laboratory, precautionary measures, prevention protocol, community guidelines, and reagents stock points, etc.

\section{Current Scenario in Mizoram}

Mizoram shares a $722 \mathrm{~km}$ long international border, sandwich between Bangladesh in the west and Myanmar in the east. International Border trade is situated in Zokhawthar Village bordering Myanmar though it is not connected with any air or sea route. It shares a national boundary with Assam in the north, Manipur in the north-east and Tripura in the West. $^{21}$ International transportation to and from neighbouring countries could make it a possible route of spreading communicable diseases. The first case of COVID-19 in Mizoram was diagnosed on 24 March 2020. There were 418 active cases with five mortality from 3765 infected patients as of 26 November $2020 .^{22}$

The government of Mizoram along with nongovernmental organizations have taken various measures to suppress and curb the spread of COVID -19. Their initiatives taken were briefly described by Zothantluanga et al., who also described the incidence and prevalence in Mizoram. ${ }^{23}$

\section{Screening and Diagnosis}

The SARS-CoV-2 suspected samples were processed for a diagnostic test in biosafety level-2 and higher laboratories. Research studies such as isolation and characterization of the virus are not recommended except in Biosafety level-3 laboratory or more. ${ }^{24}$ Oropharyngeal and nasopharyngeal swabs were obtained and transport in viral transport medium (VTM) for antigen detection and nucleic acid detection test, while blood samples are for the serological test. Antibody detection test was not suggested for diagnosis of acute infection due to 
possible low or undetectable antibodies in an asymptomatic population however rapid antibody test was done for screening and epidemiological surveillance purposed in various setup. SARS-CoV-2 viral RNA detection by a real-time reverse transcriptase-polymerase chain reaction (real-time PCR) in oropharyngeal and nasopharyngeal swab samples is the most reliable technique and a gold standard approved by WHO. However, no studies have defined the association between diagnostic PCR threshold cycle (CT-value) of oropharyngeal or nasopharyngeal samples with the severity of the disease. ${ }^{25,26}$

\section{Real-time PCR}

A validated qualitative real-time PCR has been developed and in-used for screening and diagnosis of COVID-19. ${ }^{27}$ SARS-CoV-2 RNA detected in a blood and stool specimen has been reported and documented, though faecal and oral transmission may not be significantly associated with the spread of the disease. ${ }^{28,29}$ Chen et al. determined that detection of viral RNA in blood and anal swab have a positive correlation with the disease severity; early monitoring of RNA in blood might benefit the disease prediction other than the respiratory sample. $^{30}$

\section{RT-PCR kits}

ICMR New Delhi approved two qualitative diagnostic RT-PCR kits in the early pandemic; RealStar SARS-CoV-2 RT-PCR kit 1.0 (Altona Diagnostic, Hamburg Germany) and Patho Detect COVID-19 kit (MY LAB, Pune, India) which has 100\% sensitivity and specificity. ${ }^{20}$ Since then, other RT-PCR kits, and closed system PCR TrueNAT and cartridgebased nucleic acid amplification test (CBNAAT) were approved for diagnosis. These closed system laboratory test has made COVID-19 testing less constraint and applicable for lower (or basic) laboratory set up.

\section{Antigen test}

Rapid antigen test (RAT) is used in routine screening among the population in quarantine, COVID Care Centre (CCC), isolation centre, containment zone, non-containment zone surveillance, and health care centre. Confirmatory diagnosis has to be done with RT-PCR in a case of developing symptoms following RAT negative result. ICMR guidelines consider a single RT-PCR, CBNAAT, TrueNat, or RAT positive as a confirmatory without repeat testing. ${ }^{31}$

\section{Treatment}

Therapeutic treatments are the backbone for reducing symptoms, morbidity, and mortality. Specific antiviral drugs for the treatment of COVID19 were in the developmental process but the road ahead remains uncertain. RNA polymerase inhibitor Remdesivir, and a broad-spectrum antiviral drug Favipiravir may be safe and harmless for short-term use, but strong evidence will be required to measure the longer-term therapy effect. ${ }^{32,33}$ Clinical trials on repurposing various antiviral, antimalarial drugs, and steroids were conducted for therapeutic purposes worldwide; some of the drugs were depicted in Table 1. Corticosteroids and glucocorticoid interventions

Table 1 | List of the drugs and vaccines for COVID-19.

\begin{tabular}{|c|c|c|}
\hline \multicolumn{2}{|r|}{ Drugs/Vaccine } & \multirow{2}{*}{$\begin{array}{l}\text { Mechanism of action } \\
\text { A nucleoside analogue inhibiting RNA dependent RNA polymerase } \\
\text { enzyme } 34,35\end{array}$} \\
\hline 1. & Remdesivir & \\
\hline 2. & Ribavirin & Protease enzymes inhibitor ${ }^{36}$ \\
\hline 3. & Favipiravir & Inhibitor of RNA dependent RNA polymerase enzymes ${ }^{32}$ \\
\hline 4. & Lopinavir/Ritonavir & Protease enzymes inhibitor ${ }^{36}$ \\
\hline 5. & Arbidol & $\begin{array}{l}\text { Selective broad-spectrum antiviral drug inhibiting the membrane } \\
\text { haemagglutinin fusion }{ }^{37,38}\end{array}$ \\
\hline 6. & Ad5 nCoV by CanSino & Non-replicating AdV5 expressing spike protein ${ }^{42}$ \\
\hline 7. & ChAd0x1 nCoV-19 by Astrazeneca & Non-replicating chimpanzee Adenovirus expressing spike protein ${ }^{42}$ \\
\hline 8. & mRNA-1273 by Moderna & mRNA expressing spike protein ${ }^{42}$ \\
\hline 9. & NVX CoV2373 by Novavax & Recombinant spike protein with matrix-M adjuvant ${ }^{42}$ \\
\hline 10. & Covaxin by Bharat Biotech & Inactivated vaccine ${ }^{43}$ \\
\hline 11. & Convalescent plasma & Contain antibody against SARS-CoV-241 \\
\hline
\end{tabular}


were proposed in viral pneumonia to mitigate inflammation on different organs. ${ }^{39}$ Dexamethasone in a preliminary report of clinical trial shows a shorter duration of hospitalization and lower mortality than the usual care group. ${ }^{40}$ Convalescent plasma therapy (CPT) containing high titers of neutralizing antibodies could be an alternative therapy for the treatment of COVID-19 patients. $^{41} \mathrm{WHO}$, national guidelines, and evidence-based treatment should be considered to give the best pharmaceutical care.

Various research centres and pharmaceutical industries have developed a vaccine for trial. CanSino Biological Inc. in partnership with the Academy of Military Medical Science, China developed a non-replicating AdV5 based vaccine that expressed unmodified spike protein, and this vaccine is currently licensed for use in the Chinese military. ${ }^{42}$ Bharat Biotech in collaboration with NIV Pune and ICMR developed first India's indigenous COVID-19 vaccine Covaxin, it was approved for a clinical trial by the Drug Controller General of India (DCGI). Other vaccine candidates developed in India such as ZyCoV-D by Zydus Cadila, Covishield by Serum Institute of India, and Sputinik by Dr. Reddy's Laboratory Limited and Sputnik LLC were also approved for clinical trials in India by DCGI. ${ }^{43}$

\section{Prevention}

SARS-CoV-2 spread through direct and indirect transmission, causing mild to severe infection among the different age groups. The geriatric population and patients with underlying diseases are highly prone to complications. ${ }^{11}$ Preventive measures include repeated hand washing, wearing a mask, social distancing, avoiding public gatherings, traveling, and self-quarantine if exposed to cases or traveling in an affected area. Union government and state authority hurdle to minimize the spread of the disease by setting up different protocols and rules. Preventive measures such as population surveillance, strict vigilance of containment zone, contact tracing, travel advisory, restriction of movement and gathering in public places guidelines, etc. were implemented subsequently. Details of implemented guidelines and protocols are accessible from MoHFW, Government of India website, and MoHFW Government of Mizoram website as well. ${ }^{19,44}$

\section{Emerging and Re-emerging Infectious}

\section{Diseases}

Based on the definition, some diseases may emerge within a specific population or geographical location causing a severe impact on public and environmental health. Susceptible host, carrier, environment, and modes of transmission play an important role in their emergence and reemergence. Dikid et al. in their review of emerging and re-emerging infectious diseases identified that six of the eight pathogens had zoonotic origin in India. An outbreak due to Nipah virus, Chikungunya virus, Crimean Congo haemorrhagic fever, Avian influenza (H5N1), and Chandipura virus were zoonotic diseases which emerged or re-emerged in the last two decades. ${ }^{2}$

Challenges in combating infectious diseases may differ from economically stable states with advanced diagnostic and research infrastructure to a limited resource set up. Public health infrastructure, laboratory test credibility services, and research will consistently threaten the health economic developments or vice versa; unless a strategic vision and an effective plan are developed to tackle the obstacle. These obstacles will eventually require the application of classy epidemiological and molecular biology technology, changes in human behaviour, policies, regional and national population perspectives. $^{45}$

Improving surveillance systems plays a great role in the implementation and defining strategy in a predictable and unpredictable disease outbreak. A seasonal and geographical variance of reported and an unknown disease epidemiological surveillance is essential to encounter an outbreak concerning the current pandemic. Basic microbiology and advance research laboratory are the basic needs in response to good public health perspectives and diagnosis of different infectious diseases. The central part of infectious disease surveillance could be based on various fields; some of the fields needed for surveillance and their associated agents are depicted in Table 2. The strategy could be focus based on disease epidemiology and burden of the infectious pathogens in different countries.

\section{Prioritizing Emerging and re-emerging infectious disease in Mizoram}

As per the Ministry of Health and Family Welfare, Government of Mizoram, there were seven disease outbreaks in 2017 to 2018; frequently an arthropodborne disease scrub typhus, which was through the bite of Orientia tsutsugamushi infected mite larvae. Five scrub typhus outbreaks were investigated under Integrated Disease Surveillance Programme (IDSP) Mizoram, including five mortality; a single case in Pangzawl, two in Thenzawl, and two in Sawleng villages respectively. ${ }^{46}$ Various arthropod-borne diseases including scrub typhus and dengue outbreaks were recorded since 2012 from different localities in Mizoram, predominantly dengue outbreak in Aizawl. ${ }^{47,48}$ Several food poisoning in different districts and a measles outbreak in Kolasib were also recorded in the IDSP. ${ }^{46}$

Tropically in a home of various flora and fauna, an interaction between wildlife and human-being happens directly or indirectly in Mizoram. It is a suitable habitat for several species of Anopheles, 
Table 2 | Important infectious disease aetiological agents need for surveillance.

\begin{tabular}{lll} 
Empiric strategy for surveillance & \multicolumn{1}{c}{ E2 } & \multicolumn{1}{c}{$\begin{array}{c}\text { Infectious agents or diseases } \\
\text { 1.534 }\end{array}$} \\
\hline 1. & Antimicrobial resistance pathogens & $\begin{array}{l}\text { ESBL producing bacteria, MRSA, ART resistance, Multi- } \\
\text { drug resistant Tuberculosis }\end{array}$ \\
\hline 2. & Vector-borne or arthropod zoonotic diseases & Malaria, Scrub typhus DENV, CHIKV, JEV \\
\hline 3. & Transfusion Transmissible Diseases & HIV, HBV, HCV, Malaria, Syphilis \\
\hline 4. & Oncogenic virus or chronic infectious diseases & HBC, HCV, HPV, HTLV, CMV \\
\hline 5. & Antenatal associated and new-born diseases & HIV, HBV, HCV, Toxoplasma, Rubella, CMV, Herpesvirus \\
\hline 6. & Diseases of travellers, immigrants, and refugees & HAV, HEV, Typhoid, Dengue, Cholera, etc. \\
\hline 7. & Infectious pathogens usable for bioterrorism & Anthrax, Botulism, Plague, Nipah virus, CCHF \\
\hline 8. & $\begin{array}{l}\text { New emerging and re-emerging infectious } \\
\text { pathogens }\end{array}$ & $\begin{array}{l}\text { *SARS associated virus, KFD, Nipah virus, West Nile } \\
\text { virus, Influenza viruses }\end{array}$ \\
\hline
\end{tabular}

Abbreviations: ESBL, Extended spectrum beta-lactamase; MRSA, Methicillin-resistant Staphylococcus aureus; ART, Antiretroviral therapy; DENV, Dengue virus; CHIKV, Chikungunya virus; JEV, Japanese encephalitis virus; HIV, Human immunodeficiency virus; HBV, Hepatitis B virus; HCV, Hepatitis C virus; HPV, Human papillomavirus; HTLV, Human Tlymphotropic virus; CMV, Cytomegalovirus; HAV, Hepatitis A virus; HEV, Hepatitis E virus; CCHF, Crimean Congo haemorrhagic fever; "SARS, Severe acute respiratory syndrome; KFD, Kyasanur Forest disease virus.

Aedes and, Culex mosquitoes; a well-known vector for spreading malaria, dengue, Chikungunya, and Japanese encephalitis diseases. Due to their diverse abundance during monsoon season; vector-borne disease outbreaks could be experienced during or post-monsoon seasonally. ${ }^{49}$ Infection due to bloodborne viruses such as Human immunodeficiency virus, Hepatitis $B$ virus, and Hepatitis $C$ virus was persistently prevalent within the population, such as among intravenous drug abusers, sex workers, etc. ${ }^{50}$ Antimicrobial-resistant bacterial, fungal, viral, and parasite infections could be a future burden for the community.

Therefore, research directing based on drugresistant pathogens could be preciously a key to control future antimicrobial therapy. Detection and documentation of unknown aetiological infectious agents through epidemiological research, surveillance and, surveys could be the baseline for implementation of prevention and control strategy for various diseases.

\section{Current situation and knowledge for future perspective}

SARS-CoV-2 pandemic has a mortality of more than 1 million reported by $\mathrm{WHO}$ on $20^{\text {th }}$ November $2020 .^{5}$ India has recorded more than 9 million cases and mortality of above one lakh. ${ }^{19}$ This could stigmatize social-psychological wellbeing, particularly among the state with no diagnostic facility, less advanced medical equipment, and infrastructure. Economically backward and unstable sections of the community may be the most vulnerable as their daily wages were serving them hand to mouth. Impact on the supply chain of medical requirements and daily essential commodities could also be a great burden for the authority in many aspects.

Health care professionals like physicians, nurses, allied health workers, etc. are at the highest risk of getting an infection. Also, nosocomial infection among the health care staff and the patient is likely to happen; though minimal with proper personal protective equipment. ${ }^{17}$ The pandemic creates a burden on blood transfusion for patients in need of blood such as in emergency surgery, trauma, anaemic and haemato-oncologic patients. As most of the blood donation drive will not be feasible or need to cancel it due to traumatic response to COVID-19, it may also decrease the donations among regular and responsible voluntary blood donors. This may discretely deprive the bloodstock in blood bank. ${ }^{51}$

Emerging and re-emerging infectious diseases could be expected from those endemic infectious agents and viruses periodically in Mizoram. ${ }^{46}$ As a matter of "One Health", it is important to detect, identify and document all kinds of infectious diseases within specific regions as it becomes one of the stepping stones in achieving an equal and safe ecosystem. Infection unknown aetiological agents from different syndromic approach diseases may not be diagnosed due to lack of infrastructure and experts in the field.

An integrated microbiology diagnostic, and advanced research laboratory is obligatory in Mizoram to strengthen the surveillance system. Implementation of different health strategies requires a diverse perspective concerning identification, cost-effective measures of diagnosis, treatment, prevention, control, and burden of the diseases. Registered ethical body approved surveillance with the consent of participants is 
greatly encouraging to avoid unethical human studies.

To conclude, experts and experienced individuals with a broad range of skills in the field of Clinical Laboratory, Infectious Diseases Epidemiology, Medical Microbiology, Clinical Virology, Public Health expert and physician's collaboration are highly encouraged to establish strong and evident infectious disease surveillance.

\section{Acknowledgment}

The authors would like to acknowledge Dr. TMA Pai Fellowship for Ph.D. Scholar, Manipal Academy of Higher Education for funding their Ph.D. Fellowship.

\section{Declaration of authors contribution}

Sangthang and Irene contribute in designing the concept, literature search, intellectual input and writing of manuscript. Rajesh contribute in intellectual input, review and correction of the manuscript.

\section{Conflict of interest}

The authors declared no conflict of interest.

\section{References}

1. Barreto, M. L., Teixeira, M. G., Carmo, E. H. (2006). Infectious diseases epidemiology. Journal of Epidemiology and Community Health, 60(3), 192-195. https://doi.org/10.1136/jech.2003.011593

2. Dikid, T., Jain, S., Sharma, A., Kumar, A., Narain, J. (2013). Emerging \& re-emerging infections in India: An overview. Indian Journal of Medical Research, 138(1), 19-31. https://www.ijmr.org.in/ article.asp?issn=0971-5916

3. Van Doorn, H. R. (2014). Emerging infectious diseases. Medicine (United Kingdom), 42(1), 60-63. https://doi.org/10.1016/j.mpmed.2013.10.014

4. World Health Organization. WHO Coronavirus Disease (COVID-19) Dashboard. https:// covid19.who.int/ (1 November 2020).

5. World Health Organization. Coronavirus Disease (COVID-19) Situation Reports. https://www.who.int/ emergencies/diseases/novel-coronavirus-2019/situationreports (26 November 2020).

6. Gorbalenya, A. E., Baker, S. C., Baric, R. S., de Groot, R. J., Drosten, C., Gulyaeva, A. A., Haagmans, B. L., Lauber, C., Leontovich, A. M., Neuman, B. W., Penzar, D., Perlman, S., Poon, L. L. M., Samborskiy, D. V., Sidorov, I. A., Sola, I., Ziebuhr, J. (2020). The species Severe acute respiratory syndrome-related coronavirus: classifying 2019-nCoV and naming it SARS-CoV-2. Nature Microbiology, 5(4), 536-544. https:// doi.org/10.1038/s41564-020-0695-Z

7. Lu, R., Zhao, X., Li, J., Niu, P., Yang, B., Wu, H., Wang, W., Song, H., Huang, B., Zhu, N., Bi, Y., Ma, X., Zhan, F., Wang, L., Hu, T., Zhou, H., Hu, Z., Zhou, W., Zhao, L., Tan, W. (2020). Genomic characterisation and epidemiology of 2019 novel coronavirus: implications for virus origins and receptor binding. The Lancet, 395(10224), 565-574. https://doi.org/10.1016/S0140-6736(20)30251-8

8. Rothan, H. A., Byrareddy, S. N. (2020). The epidemiology and pathogenesis of coronavirus disease (COVID-19) outbreak. Journal of Autoimmunity, 109, 102433. https://doi.org/10.1016/ j.jaut.2020.102433

9. World Health Organization. Disease Outbreak News (DONs). https://www.who.int/csr/don/en/ (17 August 2020).

10. Woolhouse, M. E. J., Adair, K., Brierley, L. (2014). RNA viruses: A case study of the biology of emerging infectious diseases. One Health, 1(1), 8397. https://doi.org/10.1128/microbiolspec.oh-00012012

11. Mendonça, F. T., Mendonça, F. T. (2020). Immunosuppressed patients and the risk of COVID-19: A narrative review. Clinical Oncology and Research, 101(8), 1-11. https://doi.org/10.31487/ j.cor.2020.08.17

12. Lauer, S. A., Grantz, K. H., Bi, Q., Jones, F. K., Zheng, Q., Meredith, H. R., Azman, A. S., Reich, N. G., Lessler, J. (2020). The incubation period of coronavirus disease 2019 (CoVID-19) from publicly reported confirmed cases: Estimation and application. Annals of Internal Medicine, 172(9), 577 -582. https://doi.org/10.7326/M20-0504

13. Rothe, C., Schunk, M., Sothmann, P., Bretzel, G., Froeschl, G., Wallrauch, C., Zimmer, T., Thiel, V., Janke, C., Guggemos, W., Seilmaier, M., Drosten, C., Vollmar, P., Zwirglmaier, K., Zange, S., Wölfel, R., Hoelscher, M. (2020). Transmission of 2019nCOV infection from an asymptomatic contact in Germany. New England Journal of Medicine, 382(10), 970-971. https://doi.org/10.1056/NEJMc2001468

14. World Health Organization. (n.d.). Transmission of SARS-CoV-2: implications for infection prevention precautions. https://www.who.int/newsroom/commentaries/detail/transmission-of-sars-cov-2implications-for-infection-prevention-precautions November 2020).

15. World Health Organization. Coronavirus. https:// 
www.who.int/health-topics/coronavirus\#tab=tab_3 (1 November 2020).

16. Cascella, M., Rajnik, M., Cuomo, A., Dulebohn, S. C., \& Di Napoli, R. (2020). Features, Evaluation and Treatment Coronavirus (COVID-19). StatPearls. http://www.ncbi.nlm.nih.gov/ pubmed/32150360

17. Bedford, J., Enria, D., Giesecke, J., Heymann, D. L., Ihekweazu, C., Kobinger, G., Lane, H. C., Memish, Z., Oh, M. don, Sall, A. A., Schuchat, A., Ungchusak, K., Wieler, L. H. (2020). COVID-19: towards controlling of a pandemic. The Lancet, 395 (10229), 1015-1018. https://doi.org/10.1016/S01406736(20)30673-5

18. Andrews, M., Areekal, B., Rajesh, K., Krishnan, J., Suryakala, R., Krishnan, B., Muraly, C., Santhosh, P. (2020). First confirmed case of COVID-19 infection in India: A case report. Indian Journal of Medical Research, 151(5), 490-492. https:// doi.org/10.4103/ijmr.IJMR_2131_20

19. Ministry of Health and Family Welfare, Government of India. https://www.mohfw.gov.in/ (18 August 2020).

20. Indian Council of Medical Research, New Delhi. List of COVID-19 testing Labs. https:// www.icmr.gov.in/pdf/covid/labs/ COVID_Testing_Labs_27112020.pdf (28 November 2020).

21. Mizoram Portal. State Information. https:// mizoram.gov.in/page/state-information (7 September 2020).

22. Health \& Family Welfare Department, Mizoram. COVID-19 Bulletin. https://health.mizoram.gov.in/ post/covid-19-bulletin-date-26112020 November 2020).

23. Zothantluanga, J. H., H., L., Shakya, A., Joseph H., L. (2020). COVID-19 incidence in Mizoram, India. Science Vision, 20(3), 93-105. https:// doi.org/10.33493/scivis.20.03.01

24. Interim Guidelines for Biosafety and COVID-19 । CDC. (n.d.). https://www.cdc.gov/ coronavirus/2019-ncov/lab/lab-biosafetyguidelines.html (18 June 2020).

25. Oliveira, B. A., de Oliveira, L. C., Sabino, E. C., Okay, T. S. (2020). SARS-CoV-2 and the COVID-19 disease: A mini review on diagnostic methods. Revista do Instituto de Medicina Tropical de Sao Paulo, 62, 1-8. Instituto de Medicina Tropical de Sao Paulo. https://doi.org/10.1590/S16789946202062044

26. Hernández-Huerta, M. T., Pérez-Campos Mayoral, L., Sánchez Navarro, L. M., Mayoral-Andrade, G.,
Pérez-Campos Mayoral, E., Zenteno, E., \& PérezCampos, E. (2020). Should RT-PCR be considered a gold standard in the diagnosis of COVID-19? In Journal of Medical Virology. https://doi.org/10.1002/ jmv. 26228

27. World Health Organization. Laboratory biosafety guidance related to coronavirus disease 2019 (COVID-19): interim guidance. https://apps.who.int/ iris/handle/10665/331138 (12 February 2020).

28. Wang, W., Xu, Y., Gao, R., Lu, R., Han, K., Wu, G., Tan, W. (2020). Detection of SARS-CoV-2 in Different Types of Clinical Specimens. Journal of the American Medical Association, 323(18), 18431844. https://doi.org/10.1001/jama.2020.3786

29. Tang, A., Tong, Z., Wang, H., Dai, Y., Li, K., Liu, J., Wu, W., Yuan, C., Yu, M., Li, P., Yan, J. (2020). Detection of Novel Coronavirus by RT-PCR in Stool Specimen from Asymptomatic Child, China. Emerging Infectious Diseases, 26(6), 1337-1339. https://doi.org/10.3201/eid2606.200301

30. Chen, W., Lan, Y., Yuan, X., Deng, X., Li, Y., Cai, X., Li, L., He, R., Tan, Y., Deng, X., Gao, M., Tang, G., Zhao, L., Wang, J., Fan, Q., Wen, C., Tong, Y., Tang, Y., Hu, F., Tang, X. (2020). Detectable 2019$\mathrm{nCoV}$ viral RNA in blood is a strong indicator for the further clinical severity. Emerging Microbes $\mathcal{E}$ Infections, 9(1), 469-473. https:// doi.org/10.1080/22221751.2020.1732837

31. Indian Council of Medical Research, New Delhi. Testing Strategy. https://www.icmr.gov.in/ cteststrat.html (30 October 2020).

32. Pilkington, V., Pepperrell, T., Hill, A. (2020). A review of the safety of Favipiravir - a potential treatment in the COVID-19 pandemic? Journal of Virus Eradication, 6(2), 45-51. https:// doi.org/10.1016/S2055-6640(20)30016-9

33. Agrawal, U., Raju, R., Udwadia, Z. F. (2020). Favipiravir: A new and emerging antiviral option in COVID-19. Medical Journal Armed Forces India, 76 (4), 370-376. https://doi.org/10.1016/ j.mjafi.2020.08.004

34. Beigel, J. H., Tomashek, K. M., Dodd, L. E., Mehta, A. K., Zingman, B. S., Kalil, A. C., Hohmann, E., Chu, H. Y., Luetkemeyer, A., Kline, S., Lopez de Castilla, D., Finberg, R. W., Dierberg, K., Tapson, V., Hsieh, L., Patterson, T. F., Paredes, R., Sweeney, D. A., Short, W. R., Lane, H. C. (2020). Remdesivir for the treatment of Covid-19 - Final report. New England Journal of Medicine, 383(19), 1813-1826. https://doi.org/10.1056/NEJMoa2007764

35. Study to Evaluate the Safety and Antiviral Activity of Remdesivir (GS-5734 ${ }^{T M}$ ) in Participants with Severe 
Coronavirus Disease (COVID-19). ClinicalTrial.gov. https://clinicaltrials.gov/ct2/show/NCT04292899? term=remdesivir\&draw=2\&rank=10 $(28$ November 2020)

36. Hung, I. F. N., Lung, K. C., Tso, E. Y. K., Liu, R., Chung, T. W. H., Chu, M. Y., Ng, Y. Y., Lo, J., Chan, J., Tam, A. R., Shum, H. P., Chan, V., Wu, A. K. L., Sin, K. M., Leung, W. S., Law, W. L., Lung, D. C., Sin, S., Yeung, P., Yuen, K. Y. (2020). Triple combination of interferon beta- $1 \mathrm{~b}$, lopinavirritonavir, and ribavirin in the treatment of patients admitted to hospital with COVID-19: an openlabel, randomised, phase 2 trial. The Lancet, 395 (10238), 1695-1704. https://doi.org/10.1016/S01406736(20)31042-4

37. Vankadari, N. (2020). Arbidol: A potential antiviral drug for the treatment of SARS-CoV-2 by blocking trimerization of the spike glycoprotein. International Journal of Antimicrobial Agents, 56(2), 105998. j.ijantimicag.2020.105998

38. Arbidol for COPD Exacerbations. ClinicalTrials.gov. https://clinicaltrials.gov/ct2/show/NCT03851991? term=arbidol\&draw $=2 \&$ rank=3 $\quad(28 \quad$ November 2020)

39. World Health Organization. (n.d.) WHO welcomes preliminary results about dexamethasone use in treating critically ill COVID -19 patients. https://www.who.int/news-room/detail/16 -06-2020-who-welcomes-preliminary-results-aboutdexamethasone-use-in-treating-critically-ill-covid-19patients (17 August 2020)

40. Dexamethasone in Hospitalized Patients with Covid-19 - Preliminary Report. (2020). New England Journal of Medicine. https://doi.org/10.1056/ nejmoa2021436

41. Rajendran, K., Krishnasamy, N., Rangarajan, J., Rathinam, J., Natarajan, M., Ramachandran, A. (2020). Convalescent plasma transfusion for the treatment of COVID-19: Systematic review. Journal of Medical Virology, 92(9), 1475-1483. https:// doi.org/10.1002/jmv.25961

42. Krammer, F. (2020). SARS-CoV-2 vaccines in development. Nature, 586(7830), 516-527. https:// doi.org/10.1038/s41586-020-2798-3

43. Vaccine information, ICMR New Delhi. COVID-19 Vaccine. (n.d.). https://vaccine.icmr.org.in/covid-19vaccine (28 November 2020).
44. Health \& Family Welfare Department, Mizoram. (n.d.-b). COVID-19 Bulletin. https:// health.mizoram.gov.in/post/covid-19-dailybulletin-1782020 (18 August 2020)

45. Bernardo W. M. (2017). Public health policies and scientific evidence. Einstein (Sao Paulo, Brazil), 15 (4), 7-10. https://doi.org/10.1590/S167945082017ED4314

46. Health \& Family Welfare Department, Mizoram. (n.d.-c). Integrated Disease Surveillance Programme. https://health.mizoram.gov.in/page/ idsp1532332535 (1 November 2020)

47. Lalchhandama, K. (2017). Rickettsiosis as a critical emerging infectious disease in India. Science Vision, 17(4), 247-256. https://doi.org/10.33493/ scivis.17.04.09

48. Vanlalruati, RSC; Lalhmingmawii, (2019). Dengue infections and circulating serotypes in Mizoramnorth eastern part of India, from 2016 to 2018. Journal of Medical Science and Clinical Research, 7(8), 129-135. https://doi.org/10.18535/jmscr/v7i8.22

49. Vanlalruia, K., Senthilkumar, N., Gurusubramanian, G. (2014). Diversity and abundance of mosquito species in relation to their larval habitats in Mizoram, North Eastern Himalayan region. Acta Tropica, 137, 1-18. https:// doi.org/10.1016/j.actatropica.2014.04.026

50. Chelling, P. K., Borkakoty, B. J., Chetia, M., Das, H. K., Mahanta, J. (2008). Risk of hepatitis C infection among injection drug users in Mizoram, India. Indian Journal of Medical Research, 128(5), 640-646.

51. Miller, H. (n.d.). Blood donations needed during coronavirus pandemic. CNBC. https:// www.cnbc.com/2020/03/23/blood-donations-neededduring-coronavirus-pandemic.html (18 June 2020)

52. Cantón, R. (2005). Role of microbiology laboratory in infectious disease surveillance, alert and response. Clinical Microbiology and Infection, Supplement, 11(1), 3-8. https://doi.org/10.1111/ j.1469-0691.2005.01081.x

53. Morens, D. M., Folkers, G. K., Fauci, A. S. (2004). The challenge of emerging and re-emerging infectious diseases. Nature, 430(6996), 242-249. https://doi.org/10.1038/nature02759

54. Saha, S., Muddegowda, P.H., Ramachandran, T.L., Jeyakumar, J.D, Datla, P.T. (2015). Transfusion transmitted infection-An update in India. National Journal of Laboratory Medicine, 4(4), 77-82. 